\title{
The effects of ispaghula on rat caecal fermentation and stool output
}

\author{
BY CHRISTINE A. EDWARDS*, JACQUELINE BOWEN, \\ W. GORDON BRYDON, AND MARTINA. EASTWOOD \\ Gastrointestinal Laboratory, University of Edinburgh, Western General Hospital, \\ Edinburgh EH4 $2 X U$
}

(Received 14 March 1991 - Accepted 1 August 1991)

\begin{abstract}
The colonic fermentation of ispaghula, a mucilage from Plantago ovata composed mainly of arabinoxylans, and its effects on stool output and caecal metabolism were investigated. Four groups of eight rats were fed on a basal diet $(45 \mathrm{~g}$ non-starch polysaccharides $/ \mathrm{kg}$ ) for $28 \mathrm{~d}$. The diet was then supplemented with ispaghula $(\mathrm{g} / \mathrm{kg} ; 0,5,15$ or 50$)$ for $28 \mathrm{~d}$. Ispaghula increased stool dry weight and apparent wet weight but faecal water-holding capacity (amount of water held per $\mathbf{g}$ dry faecal material at $0.2 \mathrm{mPa}$ ) was unchanged. The extent of faecal drying in the metabolism cages was measured for rats fed on the basal diet and $50 \mathrm{~g}$ ispaghula/ $\mathrm{kg}$ diet. At the faecal output levels encountered, only an $8 \%$ loss of wet weight would be predicted over $24 \mathrm{~h}$ and this was independent of diet. Faecal short-chain fatty acid (SCFA) concentration did not change but SCFA output increased. The molar proportion of SCFA as propionic acid increased and faecal $\mathrm{pH}$ was reduced. Values from pooled faecal samples suggested that approximately $50 \%$ of the ingested ispaghula was excreted by the $50 \mathrm{~g}$ ispaghula $/ \mathrm{kg}$ diet group. Diaminopimelic acid (a constituent of bacterial cells) concentrations fell but output was unchanged indicating no change in bacterial mass. Similar changes were seen in the caecal contents but caecal pH and SCFA were unaffected. Ispaghula increased both caecal and colonic tissue wet weight and colonic length. Our results suggest that ispaghula is partly fermented in the rat caecum and colon, and loses its water-holding capacity. However, it is still an effective stool bulker and acts mainly by increasing faecal water by some unknown mechanism.
\end{abstract}

Ispaghula: Plantago ovata: Caecal fermentation: stool bulking

Ispaghula husk is the epidermis from the seed of Plantago ovata. The chief constituent is a mucilage which contains a hemicellulose composed mainly of arabinoxylans $(\beta(1-4)$ linked D-xylo pyranosyl units; Sandhu et al. 1981). Ispaghula is an effective stool-bulking agent and is widely used in treating constipation. It is thought to increase stool output by virtue of its water-holding capacity and resistance to colonic fermentation. In vitro studies (Rasmussen et al. 1987; Tomlin et al. 1989), however, have shown at least partial degradation of ispaghula, and in vivo studies in rat and in man have shown a wide range of degradation from 32 to $87 \%$ (Prynne \& Southgate, 1979; Sosulski \& Cadden, 1982; Nyman \& Asp, 1985). These studies are difficult to compare as the dose of ispaghula ingested varied from 30 to $100 \mathrm{~g} / \mathrm{kg}$ diet and the period of feeding from 1 to 3 weeks. None of these studies investigated the effects of ispaghula on caecal contents. The fermentation of ispaghula and resultant production of short-chain fatty acids (SCFA) may have important metabolic implications. SCFA are believed to be trophic agents for the colonic mucosa (Sakata, 1987) and may be used as a preferential energy source by the colonic epithelial cells (Roediger, 1982). Production of propionic acid in particular may influence

\footnotetext{
* Present address: Department of Human Nutrition, Yorkhill Hospitals, Glasgow G3 8SJ.
} 
Table 1. Composition of basal diet* $(\mathrm{g} / \mathrm{kg}$ dry weight $)$

\begin{tabular}{lc}
\hline \hline Cornflour & 720 \\
Danpro A & 200 \\
Soya-bean oil & 30 \\
Vitamin and mineral mix & 50 \\
Digestible fat & $29 \cdot 9$ \\
Digestible protein & 129 \\
Starch & $629 \cdot 5$ \\
Sugar & $22 \cdot 8$ \\
Total dietary fibre (NSP) $\dagger$ & 45 \\
\hline
\end{tabular}

NSP, non-starch polysaccharides.

* Supplied by Special Diet Services Ltd, Whitham, Essex.

Values quoted are from information provided by the suppliers. Danpro A is soya-bean-protein concentrate.

$\uparrow$ Total dietary fibre was measured in Cambridge by the Englyst method (Englyst \& Cummings, 1984).

the metabolism of glucose and cholesterol in the liver (Chen \& Anderson, 1984; Demigne et al. 1986).

The aims of the present study were to determine the extent of ispaghula fermentation in the rat caecum and colon, and to investigate the effect of increasing doses of ispaghula on caecal and faecal water, SCFA and bacterial content.

Rats were fed on a basal diet ( $45 \mathrm{~g}$ non-starch polysaccharides $/ \mathrm{kg}$; Walter et al. 1986) to which was added different amounts of ispaghula $(0-50 \mathrm{~g} / \mathrm{kg})$. The diets were fed over a period of 4 weeks to allow adaptation to the fibre and the expression of ispaghuladegradation enzymes. Data on stool output were obtained while the rats were housed in metabolism cages for $3 \mathrm{~d}$ and caecal contents were then taken for analysis allowing comparison of caecal and faecal constituents.

\section{METHODS}

Animals

A total of thirty-two male Wistar rats, initial weight approximately $150 \mathrm{~g}$, were fed on a basal diet (Special Diet Services Ltd, Witham, Essex; Table 1) for 4 weeks. They were housed together in groups of up to five and maintained within the facilities of the Animal Unit, Western General Hospital, Edinburgh. The room was regulated to a $12 \mathrm{~h}$ light $-12 \mathrm{~h}$ dark schedule.

\section{Diets}

After 4 weeks on the basal diet the animals were divided into four groups of eight animals matched for weight. Each group was then maintained on the basal diet supplemented with either $0,5,15$ or $50 \mathrm{~g}$ ispaghula/ $\mathrm{kg}$ for a further 4 weeks. Animals were allowed ad lib. access to feed and water. Weight gain was monitored weekly. For $3 \mathrm{~d}$ at the end of the test diet period the animals were housed separately in metabolism cages.

\section{Sample collection and analysis}

While the animals were housed in the metabolism cages, food intake was measured. Faeces were collected twice daily at 09.00 and 15.00 hours, weighed, the $\mathrm{pH}$ measured and then divided into two portions; one frozen still wet for water-holding capacity measurement and the other adjusted to $\mathrm{pH} 9$ with sodium hydroxide, frozen at $-20^{\circ}$, freeze-dried and reweighed. 
Since there may be some water loss from faecal pellets before freezing, a simple experiment was carried out to assess this. Fresh faeces (collected within $1 \mathrm{~h}$ of excretion) from rats fed on the basal diet and the $50 \mathrm{~g}$ ispaghula $/ \mathrm{kg}$ diet were placed in a universal container similar to the faecal collection tubes, weighed and left uncovered for $24 \mathrm{~h}$ at the same temperature $\left(22^{\circ}\right)$ as the metabolism cages. The tubes were then reweighed to determine water loss.

After $3 \mathrm{~d}$ the animals were killed by diethyl ether overdose. The caecum and complete colon were removed. The two were separated and the contents carefully removed. The weights of caecal and colonic contents were measured and the contents treated in an identical manner to the faecal material. The caecum and colon were carefully dissected free from fat and mesentery and washed with saline ( $9 \mathrm{~g}$ sodium chloride/l). They were then blotted and weighed.

Samples of freeze-dried faeces and caecal contents were used for analysis of SCFA (gas-liquid chromatography; Spiller et al. 1980) and 2-6-diaminopimelic acid (DAPA; Czerkawski, 1974). Faecal samples from the last $2 \mathrm{~d}$ in the metabolism cages were pooled and used for all analyses. Collections from the first day were not analysed to allow for the adaptation of the animals to the cages. Animals were placed in the metabolism cages in the morning. The faeces were collected before removing the animals on the final day. Any faeces passed during handling on the final day after removal from the cages were regarded as colonic contents.

\section{Water-holding capacity}

This is defined as the amount of water held by $1 \mathrm{~g}$ dry weight of material against an osmotic pressure of $0.2 \mathrm{mPa}$. The water-holding capacity of faeces and caecal contents was measured by a dialysis technique (Robertson \& Eastwood, 1981). Dialysis tubing (Medicell International Ltd, London) size 4-22/32" was cut into $100 \mathrm{~mm}$ lengths and soaked overnight in $10 \mathrm{~g}$ sodium azide/l. Faeces and caecal material (equivalent to $100 \mathrm{mg}$ dry weight) were soaked overnight in $10 \mathrm{~g}$ sodium azide/l to a total volume of $10 \mathrm{ml}$. The faeces or caecal material were then placed inside the dialysis tubing and closed with waxed dental floss. These dialysis bags were placed in individual $150 \mathrm{ml}$ conical flasks containing $50 \mathrm{ml}$ polyethylene glycol (molecular weight 10000) at an osmolarity required to produce an osmotic pressure of $0.2 \mathrm{mPa}$. The flasks were sealed and shaken in an orbital shaker for $72 \mathrm{~h}$ at room temperature. The bags were then removed, blotted dry and weighed in a dry sealed universal container. The wet weight of the contents was calculated by subtracting the weight of the wet empty bag and the universal container. The bag was then frozen, freezedried and reweighed to calculate the dry weight of the sample.

\section{Statistical analysis}

The results from rats fed on ispaghula were compared with the results for the rats fed on the control basal diet using one-way analysis of variance (ANOVA) and Student's $t$ test. The effect of increasing dose of ispaghula was assessed by rank correlation.

\section{RESULTS}

Weight gain and food intake

There was no statistically significant difference between the intake of food dry matter apart from the ispaghula, or the weight gain of any of the groups (Table 2). Animals on $50 \mathrm{~g}$ ispaghula $/ \mathrm{kg}$ tended to eat more food to compensate for the dilution of energy by the fibre, but this did not achieve statistical significance. 
Table 2. Food intake and weight gain of rats on diets supplemented with ispaghula* (Mean values for eight rats)

\begin{tabular}{|c|c|c|c|c|c|c|}
\hline \multirow[t]{2}{*}{ Dietary treatment... } & \multirow[b]{2}{*}{ Basal } & \multicolumn{3}{|c|}{$\begin{array}{l}\text { Ispaghula supplement } \\
\qquad(\mathrm{g} / \mathrm{kg})\end{array}$} & \multirow{2}{*}{$\begin{array}{l}\text { Pooled } \\
\text { SE }\end{array}$} & \multirow{2}{*}{$\begin{array}{c}\text { Rank } \\
\text { correlation } \dagger\end{array}$} \\
\hline & & 5 & 15 & 50 & & \\
\hline Food intake $(\mathrm{g} / \mathrm{d})$ & $21 \cdot 6$ & $22 \cdot 7$ & $22 \cdot 1$ & 24 & 0.6 & NS \\
\hline Ispaghula intake $(\mathrm{g} / \mathrm{d})$ & 0 & $0 \cdot 1$ & 0.34 & $1 \cdot 2$ & 0.02 & $P<0.001$ \\
\hline Weight gain $(\mathrm{g} / 28 \mathrm{~d})$ & $87 \cdot 3$ & $85 \cdot 9$ & $82 \cdot 3$ & $73 \cdot 3$ & $8 \cdot 2$ & NS \\
\hline
\end{tabular}

NS, not significant

* For details of diets, see p. 474 and Table 1.

+ Significance values relate to rank correlation with ispaghula dose.

Table 3. Mean wet and dry weight, water content and water-holding capacity (WHC) of caecal contents of rats fed on diets supplemented with ispaghula $\dagger$

(Mean values for eight rats except WHC where values are for five rats)

\begin{tabular}{|c|c|c|c|c|c|c|}
\hline \multirow[t]{2}{*}{ Dietary treatment ... } & \multirow[b]{2}{*}{ Basal } & \multicolumn{3}{|c|}{$\begin{array}{l}\text { Ispaghula supplement } \\
\qquad(\mathrm{g} / \mathrm{kg})\end{array}$} & \multirow{2}{*}{$\begin{array}{c}\text { Pooled } \\
\text { SE }\end{array}$} & \multirow{2}{*}{$\begin{array}{c}\text { Rank } \\
\text { correlationt }\end{array}$} \\
\hline & & 5 & 15 & 50 & & \\
\hline Wet wt $(g)$ & $4 \cdot 19$ & $4 \cdot 63$ & $5 \cdot 06^{*}$ & 6.91 & $0 \cdot 28$ & $P<0.001$ \\
\hline Dry wt: g & 0.68 & $0 \cdot 79$ & 0.83 & $1 \cdot 10^{* *}$ & 0.06 & $P<0.0001$ \\
\hline Dry matter $(\mathrm{g} / \mathrm{l00} \mathrm{g})$ & $16 \cdot 6$ & $17 \cdot 3$ & $16 \cdot 5$ & 160 & $1 \cdot 1$ & NS \\
\hline Water content $(\mathrm{g})$ & $3 \cdot 51$ & 3.84 & $4 \cdot 23$ & $5 \cdot 82 * * *$ & $0 \cdot 27$ & $P<0.001$ \\
\hline $\mathrm{WHC}^{*}(\mathrm{~g} / \mathrm{g}$ dry $w \mathrm{t})$ & 1.47 & $1 \cdot 29$ & 1.47 & 1.55 & $0 \cdot 16$ & NS \\
\hline
\end{tabular}

NS, not significant.

Mean values were significantly different from those for basal diet: $* P<0.05, * * P<0.01,{ }^{* * *} P<0.00 \mathrm{l}$ (Student's $t$ test).

$\dagger$ For details of diets, see p. 474 and Table L.

+ Significance values relate to rank correlation with dose.

\section{Caecal analysis}

Caecal contents weight. The rats in the 15 and $50 \mathrm{~g}$ ispaghula $/ \mathrm{kg}$ groups had significantly more caecal contents than the rats in the basal group $(P<0.05$ and $P<0.001$ respectively; Table 3). This was due to an increase in caecal water $(P<0.001)$ and dry weight $(P<0.01$; Table 3$)$. The dry weight: wet weight value was unchanged. The effect of ispaghula was also supported by rank correlation $(P<0.001$; Table 3$)$.

Water-holding capacity. There was no difference in the water-holding capacity of the caecal contents of any of the groups (Table 3) by ANOVA or when compared by rank correlation.

$S C F A, p H$ and $D A P A$

There was no change in the SCFA concentration in the caecum when ispaghula was ingested, but the total amount of SCFA in the caecum increased with dose $(P<0.02$; Table $4)$. There was also an increased molar proportion of SCFA as propionic acid in the caecum of rats as ispaghula dose increased and this achieved significance at $50 \mathrm{~g}$ ispaghula $/ \mathrm{kg}$ $(P<0.01$; Table 4). Rats fed $15 \mathrm{~g}$ ispaghula/kg dry weight had a significantly higher 
Table 4. Mean short-chain fatty acid (SCFA), pH and diaminopimelic acid (DAPA) content of the caecum of rats fed on diets supplemented with ispaghulat

(Mean values for eight rats)

\begin{tabular}{|c|c|c|c|c|c|c|}
\hline \multirow[t]{2}{*}{ Dietary treatment... } & \multicolumn{4}{|c|}{$\begin{array}{l}\text { Ispaghula supplement } \\
\qquad(\mathrm{g} / \mathrm{kg})\end{array}$} & \multirow{2}{*}{$\begin{array}{c}\text { Pooled } \\
\text { SE }\end{array}$} & \multirow{2}{*}{$\begin{array}{c}\text { Rank } \\
\text { correlation }\end{array}$} \\
\hline & Basal & 5 & 15 & 50 & & \\
\hline $\begin{array}{l}\text { Total SCFA: } \\
\mu \mathrm{mol} / \mathrm{g} \text { dry wt } \\
\mu \mathrm{mol} / \mathrm{g} \text { wet wt } \\
\mu \mathrm{mol} / \text { caecum }\end{array}$ & $\begin{array}{l}471 \\
78 \cdot 8 \\
322\end{array}$ & $\begin{array}{c}489 \\
84 \cdot 1 \\
388\end{array}$ & $\begin{array}{c}483 \\
77 \cdot 7 \\
396\end{array}$ & $\begin{array}{c}432 \\
67 \cdot 3 \\
485 * *\end{array}$ & $\begin{array}{l}33 \\
6 \cdot 1 \\
34\end{array}$ & $\begin{array}{c}\text { NS } \\
\text { NS } \\
P<0.02\end{array}$ \\
\hline $\begin{array}{l}\text { Molar proportions of: } \\
\text { Acetic } \\
\text { Propionic } \\
n \text {-Butyric } \\
\text { Valeric } \\
\text { Isobutyric } \\
\text { Isovaleric } \\
\text { pH } \\
\text { DAPA: } \mu \mathrm{mol} / \mathrm{g} \mathrm{dry} \mathrm{wt} \\
\quad \mu \mathrm{mol} / \text { caecum }\end{array}$ & $\begin{array}{c}680 \\
162 \\
132 \\
15 \\
7 \\
4 \\
6.28 \\
1454 \\
986\end{array}$ & $\begin{array}{c}670 \\
166 \\
141 \\
16 \\
6 \\
3 \\
6 \cdot 3 \\
1057 \S \\
916\end{array}$ & $\begin{array}{c}612^{*} \\
177 \\
192^{*} \\
10^{*} \\
5 \\
3 \\
6 \cdot 33 \\
1007^{* * *} \\
833\end{array}$ & $\begin{array}{c}662 \\
225^{* *} \\
94 \\
10^{*} \\
6 \\
3 \\
6 \cdot 38 \\
922^{* * *} \\
1009\end{array}$ & $\begin{array}{l}18 \\
11 \\
16 \\
0 \cdot 13 \\
0 \cdot 14 \\
0 \cdot 09 \\
0 \cdot 09 \\
69 \\
90\end{array}$ & $\begin{array}{c}\text { NS } \\
P<0 \cdot 01 \\
\text { NS } \\
P<0.01 \\
\text { NS } \\
\text { NS } \\
\text { NS } \\
P<0.001 \\
\text { NS }\end{array}$ \\
\hline
\end{tabular}

NS, not significant.

Mean values were significantly different from those for basal diet: ${ }^{*} P<0.05,{ }^{* *} P<0 \cdot 01,{ }^{* * *} P<0 \cdot 001$ (Students $t$ test after analysis of variance).

+ For details of diets, see p. 474 and Table 1 .

\$ Significance values relate to rank correlation with ispaghula dose.

$\$ n 5$ due to insufficient material.

proportion of $n$-butyric acid $(P<0 \cdot 05)$, but this was not evident in the $50 \mathrm{~g}$ ispaghula $/ \mathrm{kg}$ group (Table 4). A significantly lower proportion of valeric acid was seen as ispaghula dose increased. Caecal pH was unaffected by ispaghula (Table 4). DAPA concentrations fell with ispaghula intake but the total amount remained unchanged (Table 4).

\section{Caecal and colonic tissue weights}

There was a significant increase in the weight of the caecal and colonic tissue wet weights of rats fed on increasing doses of ispaghula $(P<0.001$, Table 5); colonic length also increased $(P<0.001$, Table 5).

\section{Faecal analysis}

Faecal output. Faecal output increased with ispaghula intake and was greatest in the group of rats fed on $50 \mathrm{~g}$ ispaghula $/ \mathrm{kg}$ dry weight (Table $6 ; P<0.001$ compared with the basal diet). This was due to a highly significant increase in faecal water $(P<0.001)$ and a smaller but significant increase in dry weight $(P<0.02$, Table 6$)$. This was reflected by a decrease in dry weight: wet weight as ispaghula intake increased $(P<0.001$; Table 6). Measurement of faecal water loss by evaporation before freezing showed a relationship between initial weight and water loss but this was independent of diet (Fig. 1). The faecal output of rats in all groups exceeded $2 \mathrm{~g} / \mathrm{d}$ and, thus, a fairly consistent loss of about $8 \%$ wet weight would be predicted.

Water-holding capacity. There was no significant difference in the water-holding capacity of the faeces in any of the groups as ispaghula intake increased (Table 6).

$S C F A$ and $p H$. Increasing the dose of ispaghula had no significant effect on SCFA 
Table 5. Effect of ispaghula on colonic length and colonic and caecal tissue weights of rats fed on diets supplemented with ispaghula $\dagger$

(Mean values for eight rats)

\begin{tabular}{|c|c|c|c|c|c|c|}
\hline \multirow[t]{2}{*}{ Dietary treatment... } & \multicolumn{4}{|c|}{$\begin{array}{l}\text { Ispaghula supplement } \\
\qquad(\mathrm{g} / \mathrm{kg})\end{array}$} & \multirow{2}{*}{$\begin{array}{l}\text { Pooled } \\
\text { SE }\end{array}$} & \multirow{2}{*}{$\begin{array}{c}\text { Rank } \\
\text { correlation }\end{array}$} \\
\hline & Basal & 5 & 15 & 50 & & \\
\hline Colonic length $(\mathrm{mm})$ & 173 & 174 & 193 & $219 * * *$ & 6 & $P<0.001$ \\
\hline $\begin{array}{l}\text { Colonic tissue wt }(\mathrm{g} / \mathrm{kg} \\
\text { body-wt) }\end{array}$ & $3 \cdot 32$ & 3.49 & $3.93 * *$ & $5 \cdot 45^{* * *}$ & 0.2 & $P<0.001$ \\
\hline $\begin{array}{l}\text { Caecal tissue wt (g/kg } \\
\text { body-wt) }\end{array}$ & 1.75 & $1 \cdot 64$ & 1.85 & $2 \cdot 32^{* * *}$ & 0.09 & $P<0.001$ \\
\hline
\end{tabular}

Mean values were significantly different from those for basal diet: ${ }^{* *} P<0.01,{ }^{* * *} P<0.001$ (Student's $t$ test after analysis of variance).

$\dagger$ For details of diets, see p. 474 and Table 1.

$\$$ Significance values relate to rank correlation with ispaghula dose.

Table 6. The effect of ispaghula on mean faecal output, faecal water, water-holding capacity (WHC) and faecal fibre of rats fed on diets containing ispaghulat

(Mean values for eight rats)

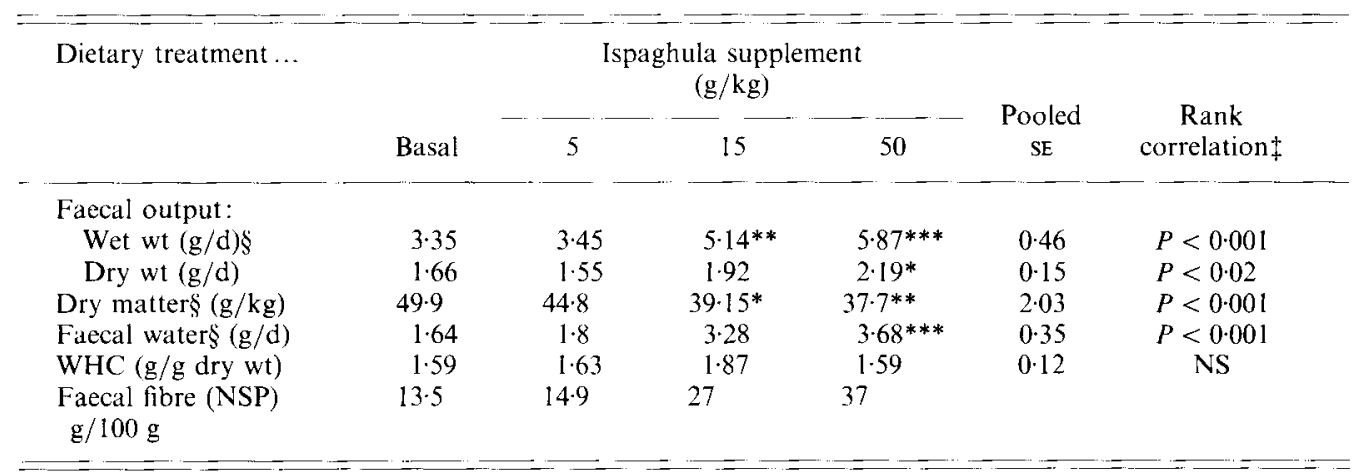

NS, not significant; NSP, non-starch polysaccharide.

Mean values were significantly different from those for basal diet: $* P<0.05, * * P<0.01, * * * P<0.00$ l (Student's $t$ test after analysis of variance).

+ For details of diets, see p. 474 and Table 1.

\$ Significance values relate to rank correlation with ispaghula dose.

$\S$ Assuming $8 \%$ water loss due to evaporation.

concentration per $\mathrm{g}$ wet or dry weight but, as a result of the increased faecal output seen with $50 \mathrm{~g}$ ispaghula $/ \mathrm{kg}$ dry weight, total SCFA output increased significantly $(P<0.001$, Table 7). There was an increased molar proportion of SCFA as propionic acid in rats fed on $50 \mathrm{~g}$ ispaghula $/ \mathrm{kg}$ but this did not achieve statistical significance. In contrast, valeric, iso-valeric and isobutyric acid output decreased $(P<0 \cdot 001$; Table 7$)$. Faecal pH was significantly reduced by increasing the concentration of ispaghula ingested (Table $7 ; P<$ $0.001)$.

$D A P A$. The concentration of DAPA decreased significantly in the faeces with ispaghula ingestion (Table 7) but total output was unchanged (Table 7). 


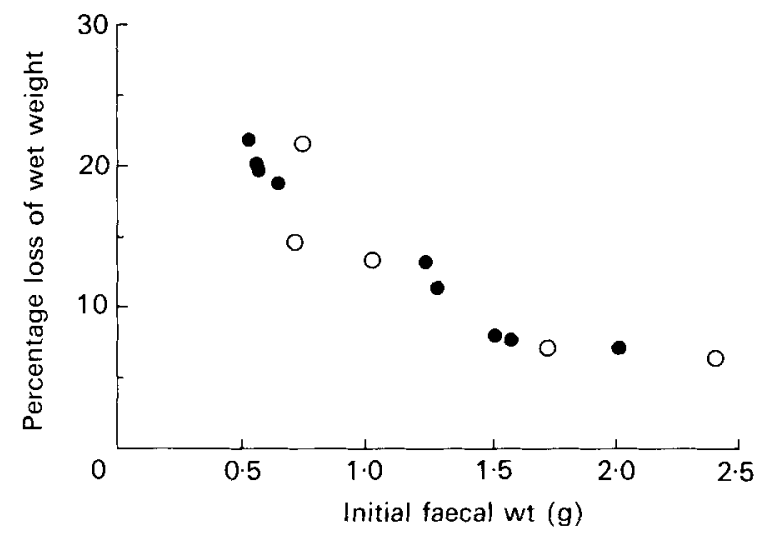

Fig. I. The weight loss of fresh faeces from rats fed on either a basal diet ( $45 \mathrm{~g}$ non-starch polysaccharides $/ \mathrm{kg}$; 0 ) or supplemented with $50 \mathrm{~g}$ ispaghula $/ \mathrm{kg}(\mathbf{O})$ over $24 \mathrm{~h}$ in conditions simulating the metabolism cage, as related to initial faecal pellet weight. Fresh faecal samples were collected and divided into individual or groups of pellets to give a range of initial faecal weights for measurement of water loss.

Table 7. Short-chain fatty acid (SCFA), pH and 2-6-diaminopimelic acid (DAPA) content of faeces of rats fed on diets supplemented with ispaghula $\dagger$

(Mean values for eight rats)

\begin{tabular}{|c|c|c|c|c|c|c|}
\hline \multirow[t]{2}{*}{ Dietary treatment } & \multirow[b]{2}{*}{ Basal } & \multicolumn{3}{|c|}{$\begin{array}{l}\text { Ispaghula supplement } \\
\qquad(\mathrm{g} / \mathrm{kg})\end{array}$} & \multirow{2}{*}{$\begin{array}{l}\text { Pooled } \\
\text { SE }\end{array}$} & \multirow{2}{*}{$\begin{array}{c}\text { Rank } \\
\text { correlation }\end{array}$} \\
\hline & & 5 & 15 & 50 & & \\
\hline \multicolumn{7}{|l|}{ Total SCFA: } \\
\hline$\mu \mathrm{mol} / \mathrm{g}$ dry wt & $76 \cdot 3$ & $76 \cdot 8$ & $84 \cdot 2$ & $108 \cdot 7$ & $13 \cdot 1$ & NS \\
\hline$\mu \mathrm{mol} / \mathrm{g}$ wt wt\$ & $38 \cdot 1$ & $30 \cdot 4$ & $30 \cdot 9$ & $39 \cdot 9$ & $5 \cdot 1$ & NS \\
\hline$\mu \mathrm{mol} / \mathrm{d}$ & $110 \cdot 4$ & $98 \cdot 2$ & $177 \cdot 2$ & $238 \cdot 1^{* * *}$ & $71 \cdot 6$ & $P<0.01$ \\
\hline \multicolumn{7}{|c|}{ Molar proportions of: } \\
\hline Acetic & 800 & 795 & 837 & 786 & 21 & NS \\
\hline Propionic & 76 & 82 & 63 & 146 & 16 & NS \\
\hline$n$-butyric & 48 & 44 & 46 & 50 & 10 & NS \\
\hline Valeric & 21 & 20 & 15 & $10^{* * *}$ & 2 & $P<0.001$ \\
\hline Isobutyric & 20 & 20 & 22 & $9 * * *$ & 3 & $P<0.001$ \\
\hline Isovaleric & 21 & 19 & $13 * *$ & $7 * * *$ & 2 & $P<0.001$ \\
\hline $\mathrm{pH}$ & 7.59 & $7 \cdot 86$ & $7 \cdot 09^{*}$ & $6 \cdot 69^{* * *}$ & $0 \cdot 17$ & $P<0.001$ \\
\hline \multicolumn{7}{|l|}{ DAPA : } \\
\hline$\mu \mathrm{mol} / \mathrm{g} \mathrm{dry} \mathrm{wt}$ & 1144 & $1010^{*}$ & $873 * * *$ & $900^{* * *}$ & 36 & $P<0.005$ \\
\hline$\mu \mathrm{mol} / \mathrm{d}$ & 1784 & 1530 & 1739 & 1971 & 162 & NS \\
\hline
\end{tabular}

NS, not significant.

Mean values were significantly different from those for basal diet: ${ }^{*} P<0 \cdot 05$, ${ }^{* * *} P<0.001$ (Student's $t$ test after analysis of variance).

+ For details of diets, see p. 474 and Table 1.

+ Significance values relate to rank correlation with ispaghula dose.

$\S$ Assuming $8 \%$ water loss by evaporation.

Faecal fibre. Pooled samples of faeces from each group and samples of the diets were sent to the laboratory of Dr H. Englyst, Dunn Nutritional Unit, Cambridge for fibre analysis. Fibre (non-starch polysaccharides) accounted for $370 \mathrm{~g} / \mathrm{kg}$ faecal dry matter of the $50 \mathrm{~g}$ ispaghula $/ \mathrm{kg}$ dry weight group giving a daily excretion of approximately $0.81 \mathrm{~g}$ per rat 
(Table 6). Ispaghula assayed as $990 \mathrm{~g}$ fibre $/ \mathrm{kg}$. Since the group receiving the basal diet excreted $0.22 \mathrm{~g}$ fibre/d per rat the amount of ispaghula excreted by the $50 \mathrm{~g}$ ispaghula $/ \mathrm{kg}$ group can be calculated as approximately $0.59 \mathrm{~g} / \mathrm{d}$ per rat. Since this group were ingesting $1.2 \mathrm{~g}$ ispaghula $/ \mathrm{d}$, this represents a loss of $51 \%$ in the gastrointestinal tract (Table 6). Obviously, as this is a calculation based on pooled data, and food intake and stool output were measured over only $2 \mathrm{~d}$, this is very much an approximate estimate and does not take into account rat-to-rat variation. Values from the rats fed on $50 \mathrm{~g}$ ispaghula/ $\mathrm{kg}$ diet were used as these would give the best estimate of faecal losses of ispaghula.

\section{DISCUSSION}

The present study has shown that ispaghula has clear effects on caecal fermentation patterns and stool output. These effects were dose-dependent with small changes in faecal and caecal wet weight, DAPA concentrations and SCFA output when the diet was supplemented with $15 \mathrm{~g}$ ispaghula $/ \mathrm{kg}$ dry weight and highly significant changes were observed with $50 \mathrm{~g}$ ispaghula/ $\mathrm{kg}$ dry weight supplementation.

There was no change in caecal or faecal SCFA concentrations but total caecal content and total faecal SCFA output increased with ispaghula dose. Ispaghula ingestion altered the pattern of fermentation products in both caecum and faeces resulting in a higher proportion of propionic acid. This has been reported by other workers studying ispaghula fermentation by human bacteria in vitro (Ramussen et al. 1987; Tomlin et al. 1989) and may play a role in the action of ispaghula on hypercholesterolaemia (Anderson et al. 1988). Propionic acid is thought to inhibit cholesterol synthesis in the liver (Chen \& Anderson, 1984), but the significance of this effect at the levels of propionic acid which reach the liver after ispaghula fermentation is not known.

The proportions of valeric acid in the caecum, and valeric, isovaleric and isobutyric acids in the faeces were significantly reduced by ispaghula. These changes in the fermentation patterns in the caecum and colon were observed without any change in the amount of DAPA. Indeed, DAPA concentration fell due to the increase in colonic water and fibre content. This indicates that bacterial metabolism may be modulated by diet without a change in bacterial mass. However, as DAPA is not present in all bacterial cells it may also indicate a change in the type of bacteria present.

The relative proportions of acetic acid, propionic acid and butyric acid were different in the caecum and faeces with more acetic acid in the faeces. This may reflect a difference in the fermentation patterns at different sites or a differential absorption or utilization of these SCFA in the colon.

The faecal fibre measurements, although of pooled samples, indicated that there was approximately $50 \%$ loss of ispaghula as it passed though the intestinal tract. This may explain the lack of effect of ispaghula ingestion on the faecal water-holding capacity. The reduction in faecal $\mathrm{pH}$ with no change in caecal $\mathrm{pH}$ suggests that ispaghula fermentation is occurring throughout the colon and not just in the caecum. However, as the faeces were collected over a 6-18 h period the faecal $\mathrm{pH}$ may reflect events occurring outside the body where there is no compensation by bicarbonate secretion. Continued fermentation throughout the colon may explain the smaller increase in faecal dry matter than in caecal dry matter when ispaghula was fed. This resulted in a much lower dry matter content in the faeces of animals as ispaghula dose increased. Our estimate of $50 \%$ degradation of ispaghula is in agreement with studies using human volunteers (Prynne \& Southgate, 1979), but not with other studies in rats (Sosulski \& Cadden, 1982; Nyman \& Asp, 1985). This may be due to differences in the ispaghula preparation, age of rats, dose, experimental design or period of adaptation. Our test period of 4 weeks allows more time for the 
expression of degradation enzymes and the stabilization of the colonic flora (Walter et al. 1986). However, since our rats were in the metabolism cages for only $3 \mathrm{~d}$ and faeces sampled only over $2 \mathrm{~d}$, as well as the values being from pooled sample analysis, our estimate is only approximate. The values for the rats fed on $50 \mathrm{~g}$ ispaghula $/ \mathrm{kg}$ were used as these would give the best estimate of ispaghula in faeces. Different values may be obtained using the rats fed on lower doses.

The time-period our rats were in the cages was not ideal but we have measured faecal output of similar rats over $28 \mathrm{~d}$ in metabolism cages and have found that faecal output is not significantly different from the values obtained over the 2 nd $2 \mathrm{~d}$ (days $2-3$ faecal output $5 \cdot 77($ SE 0.58$) \mathrm{g} / \mathrm{d}$, day $2-286 \cdot 15(\mathrm{SE} 0 \cdot 24) \mathrm{g} / \mathrm{d}$ ).

Previous dietary studies in rats have disregarded measurements of faecal water (Nyman \& Asp, 1985; Walter et al. 1986) because of the possibility of evaporation within the metabolism cages. Many fibres, however, may have their major effect on stool weight by increasing stool water and not necessarily dry weight. In addition, the concentrations of SCFA per $g$ wet weight may be a more appropriate measure than concentration per $g$ dry weight when investigating physiological action. We measured the water loss of fresh faeces over a $24 \mathrm{~h}$ period under similar conditions to those in the metabolism cages. We found that for stool samples of greater than $1.5 \mathrm{~g}$ the water loss was only approximately $8 \%$ of the wet weight and the highest water loss was $20 \%$ for a sample of $0.5 \mathrm{~g}$. This was independent of diet. This finding supports the use of wet weight measurements and allows us to determine the action of fibre on stool water. The differences in stool water reported in the present study are much greater than can be accounted for by water evaporation. Values given in the present paper assume $8 \%$ water loss.

The greater volume of caecal contents and increased apparent stool water output suggest a reduction in colonic water absorption in the presence of ispaghula. An increased colonic secretion of water, however, would also produce this result. The increase in caecal and faecal water does not appear to be related to an increased water-holding capacity, which suggests that a large proportion of the additional water is free and not bound to fibre or bacteria. The mechanism for this reduction in fluid absorption is unclear, but may be related to fermentation products or occur secondary to a reduction in transit time. Other workers have found an increase in faecal water-holding capacity after ispaghula ingestion in the rat (Nyman \& Asp, 1985). Very little ispaghula fermentation was reported in their study and water-holding capacity was measured by a centrifugation method which gives higher results than our dialysis method. The measurement of the water-holding capacity of fibre in faeces is difficult. It is dependent on the separation of water that is bound to fibre and within bacteria from that which is loosely associated with fibre but which is available for absorption within the colon under ideal conditions of contact time. The centrifugation method for water-holding capacity probably includes a significant amount of this loosely associated water (Robertson \& Eastwood, 1981). The suction or dialysis method is based on physiological principles measuring water held against an osmotic pressure similar to that present in the human colon (Robertson \& Eastwood, 1981).

The reasons for the increased colonic and caecal tissue weights when ispaghula was ingested are unclear. The caecum and colon of germ-free rats are heavier than those of conventional rats (Gustaffson, 1982) suggesting that increased bulk, due in the case of germ-free rats to excess lumen mucus, may stimulate tissue growth. The increase in tissue weight may be due to an increase in both the mucosa and muscle of the caecum and colon. SCFA produced from the fermentation of dietary fibre in conventional rats are thought to be trophic factors for the large intestinal mucosa (Sakata, 1987). Other workers have reported that ispaghula ingestion increased cellular proliferation in the distal colon of rats 
(Goodlad et al. 1987) and the same group has recently shown that fibre increased crypt cell production rate sixfold in the colon of conventional rats but not in germ-free rats (Goodlad et al. 1989).

The present study has shown that ispaghula is fermented in the rat colon. It is not clear, however, whether the ispaghula is uniformly fermented or if certain portions of the complex are preserved. The physical properties of the residue may be quite different from those of the original material. The limited extent of ispaghula fermentation and the indications that fermentation is occurring throughout the colon suggest that the transit time may be critical.

The authors would like to thank Richardson Vick Ltd, UK for financial support.

\section{REFERENCES}

Anderson, J. W., Zettwoch, R. N., Feldman, T., Tietyen-Clark, J., Oeltgen, P. \& Bishop, W. C. (1988). Cholesterol lowering effects of Psyllium hydrophilic mucilloid for hypercholesterolaemic men. Archives of Internal Medicine 148, 292-296.

Chen, W. L. \& Anderson, J. W. (1984). Propionate may mediate the hypocholesterolemic effects of plant fibres in cholesterol fed rats. Proceedings of the Society for Experimental Biology and Medicine 175, 215-218.

Czerkawski, J. W. (1974). Methods for determining 2-6-diaminopimelic acid and 2-aminoethylphosphonic acid in gut contents. Journal of Food Science and Agriculture 25, 45-55.

Demigne, C., Yacoub, C. \& Remesey, C. (1986). Effects of absorption of large amounts of volatile fatty acids on rat liver metabolism. Journal of Nutrition 116, 77-86.

Englyst, H. N. \& Cummings, J.H. (1984). Simplified method for the measurement of total non-starch polysaccharides by gas-liquid chromatography of constituent sugars as alditol acetates. Analyst 109, 937-942.

Goodlad, R. A., Lenton, W., Ghatei, M. A., Adrian, T. E., Bloom, S. R. \& Wright, N. A. (1987), Effects of an elemental diet, inert bulk and different types of dietary fibre on the response of the intestinal epithelium to refeeding in the rat and relationship to plasma gastrin, enteroglucagon and PYY concentrations. Gut 28, $171-180$

Goodlad, R. A., Ratcliffe, B., Fordham, J. P. \& Wright, N. A. (1989). Does dietary fibre stimulate intestinal epithelial cell proliferation in germ-free rats? Gut 30, 820-825.

Gustaffson, B. E. (1982). The physiological importance of the colonic microflora. Scandinavian Journal of Gastroenterology 77, Suppl. 77, 117-131.

Nyman, M. \& Asp, N.-G. (1985). Bulk laxatives: their dietary fibre composition, degradation and faecal bulking capacity in the rat. Scandinavian Journal of Gastroenterology 20, 887-895.

Prynne, C. J. \& Southgate, D. A. T. (1979). The effects of dietary fibre on faecal excretion by human subjects. British Journal of Nutrition 41, 495-503.

Rasmussen, H. S., Holtug, K., Andersen, J. R., Krag, E. \& Mortensen, P. B. (1987). The influence of ispaghula husk and lactulose on the in vivo and in vitro production capacity of short-chain fatty acids in humans. Scandinavian Joumal of Gastroenterology 22, 406-410.

Robertson, J. A. \& Eastwood, M. A. (1981). A method to measure the water holding properties of dietary fibre using suction pressure. British Journal of Nutrition 46, 247-255.

Roediger, W. E. W. (1982). Utilization of nutrients by isolated epithelial cells of the rat colon. Gastroenterology 83, 424-429.

Sandhu, J. S., Hudson, G. J. \& Kennedy, J. F. (1981). The gel nature and structure of the carbohydrate of ispaghula husk of Plantago ovata. Carbohydrate Research 93, 247-260.

Sakata, T. (1987). Stimulatory effect of short-chain fatty acids on epithelial cell proliferation in the rat intestine: a possible explanation for trophic effects of fermentable fibre, gut microbes and luminal trophic factors. British Journal of Nutrition 58, 85-102.

Sosulski, F. W. \& Cadden, A. M. (1982). Composition and physiological properties of several sources of dietary fiber. American Journal of Food Science 47, 1472-1477.

Spiller, G. A., Chernoff, M. C., Hill, R. A., Gates, J. E., Nassar, J. J. \& Shipley, E. A. (1980). Effect of purified cellulose, pectin, and a low residue diet on faecal fatty acids, transit time and faecal weight in humans. American Journal of Clinical Nutrition 33, 754-755.

Tomlin, J., Taylor, J. S. \& Read, N. W. (1989). The effects of mixed faecal bacteria on a selection of viscous polysaccharides in vitro. Nutrition Reports International 39, 121-135.

Walter, D. J., Eastwood, M. A., Brydon, W. G. \& Elton, R. A. (1986). An experimental design to study colonic fiber fermentation in the rat: duration of feeding. British Journal of Nutrition 55, 465-479.

Printed in Great Britain 